Review Article

\title{
EXPLORATION OF THE HEALTH IMPACT OF DOUBLE BURDEN OF MALNUTRITION AMONG BANGLADESHI WOMEN
}

\author{
Ipsita Sutradhar, Mehedi Hasan*
}

Research Associate, James P Grant School of Public Health, BRAC University, Bangladesh

\author{
Accepted: 17 November 2017 \\ *Correspondence: \\ Mehedi Hasan \\ Research Associate, James P Grant School of Public Health, BRAC University, Bangladesh \\ E-mail : mehedihasan6376@gmail.com
}

Copyright: (C) the author(s), YCAB publisher and Public Health of Indonesia. This is an open-access article distributed under the terms of the Creative Commons Attribution Non-Commercial License, which permits unrestricted non-commercial use, distribution, and reproduction in any medium, provided the original work is properly cited.

\begin{abstract}
Double burden of malnutrition (DBM) is a growing concern, which refers to the coexistence of under nutrition and over nutrition within the same population. The recent increase in the prevalence of overweight and existing prevalence of underweight among Bangladeshi women clearly indicates the advent of a double burden of malnutrition in Bangladesh. Women's nutritional status is extremely important for a nation because it affects not only their own health but also the health of their children. Both under nutrition and over nutrition have the potential to make women vulnerable to various adverse health conditions as well as adverse obstetric experience and poor birth outcome. It is a timely need for policy makers of this country to come up with specific interventions for both undernourished and overnourished women considering all these factors.
\end{abstract}

Key words: Double burden of malnutrition, health impact, women, Bangladesh

\section{INTRODUCTION}

Double burden of malnutrition (DBM) is an evolving concept that first came into global concern in last decade, which denotes the co-occurrence of under nutrition and over nutrition within the same group of population. ${ }^{1} \mathrm{DBM}$ can take place at family level as well as at national level and usually represents as maternal and child malnutrition in a contemporaneous manner. DBM significantly affects the lower and middle-income countries across the continents. DBM is considered as an emerging public health concern in South East Asia. Currently, Bangladesh is also facing the challenge of Double burden of malnutrition. As a consequence of current trend of nutritional transition, over nutrition is estimated to surpass the prevalence of under nutrition in near future, though under nutrition is still predominant in Bangladesh.

\section{HEALTH IMPACT OF UNDER- WEIGHT \\ Inadequate nutrition is one of the major obstacles for attaining good health and maintaining a productive life. Under-}


nourished individuals are more prone to various communicable diseases and losing their productivity. Women's underweight is more crucial because it affects not only their own health but also the health of their children. ${ }^{2}$ Children are much more likely to be born with low birth weight (LBW) and to remain undernourished throughout their lives if their mothers are undernourished during adolescence and/or before and during pregnancy. ${ }^{3}$ This finding is true in the context of Bangladesh as well. In a Bangladeshi study, it was revealed that the children of underweight women were more likely to be undernourished in terms of height-for-age and weight-for-height. Low birth weight is closely associated with fetal and neonatal mortality and morbidity, reduced physical growth and cognitive development as well as the development of chronic diseases (e.g. diabetes mellitus, cerebrovascular disease, hypertension etc.) in their later part of life. Prematurity and low birth weight also account for nearly half of total neonatal death in Bangladesh. In a word, our results strongly suggest that women's under nutrition poses a number of short-term and long-term effect on their children's health. Therefore, prevention of under nutrition should be given high priority in national health, education, and economic agendas in Bangladesh.

\section{HEALTH IMPACT OF STUNTING}

Findings from recent studies indicate that stunting has long-term effects on cognitive development of an individual along with his/her school achievement and economic productivity. ${ }^{4}$ Stunted people are also more likely to be overweight. Stunted women are more likely to give birth small and low birth weight baby and experience bad obstetric history. ${ }^{3,5}$ Captivatingly, one study reported that, only short stature can act as an independent risk factor for cesarean delivery after controlling the possible confounders such as the history of previous Cesarean section (CS), Intra Uterine Growth Retardation (IUGR), Premature Rupture of Membrane (PROM), failed induction, labor dystocia, mal-presentations, and Cephalo Pelvic Disproportion (CPD). ${ }^{6}$ Hence, prevention of stunting among women should be made a priority in Bangladesh. And to do so, intervention should be implemented from pre-conception period to the first 2 years of life to have a truly positive impact on the linear growth of women and their offspring.

\section{HEALTH IMPACT OF MICRO- NUTRIENT DEFICIENCY}

There is evidence of a relationship between severe anemia $(\mathrm{Hb}<47 \mathrm{~g} / \mathrm{L})$ and increased maternal mortality. ${ }^{7}$ Acute onset of severe anemia $(\mathrm{Hg}<80 \mathrm{~g} / \mathrm{L})$ during pregnancy can be a primary cause of death among the patients having certain diseases like a sickle-cell disease. On the other hand, chronic anemia increases the risk of death because of hemorrhage and infection. In addition to it, anemia in pregnancy is correlated with poor birth outcomes. Globally, a fifth of early neonatal mortality and a tenth of maternal mortality are attributable to iron deficiency anemia. It also decreases cognitive development and work performance of individuals. Though several micronutrient programs are going on in Bangladesh by Government and different NGOs (BRAC, GAIN, IFPRI), the current high prevalence of anemia among women indicates that further attention is needed in this regard.

It is also well established that iodine has an influence on thyroid function of individuals and deficiency of iodine during pregnancy causes cretinism and fetal wastage. ${ }^{8}$ Zinc deficiency has also some detrimental effects like growth retardation, delayed sexual maturation (hypogonadal dwarfism), neurobehavioral abnormalities among individuals. It is also responsible 
for many communicable diseases like diarrhea, pneumonia, and malaria. Zinc deficiency in pregnancy is associated with a number of complications such as preeclampsia, premature rupture of membranes, preterm delivery, fetal growth retardation, and congenital abnormalities. ${ }^{9}$ All these findings suggesting that public health programs are urgently needed to control different micronutrient deficiencies those are prevailing among Bangladeshi women.

\section{HEALTH IMPACT OF OVER- WEIGHT AND OBESITY}

Overweight and obesity are responsible for more death globally than underweight. It is well established that excessive BMI is closely related to the development of different non-communicable diseases like type-2 diabetes mellitus, hypertension, stroke, dyslipidemia, osteoarthritis, and some cancers. ${ }^{10}$ In addition, compared to normal and low weight women, overweight and obese women are more likely to develop various pregnancy related complication like gestational diabetes, preeclampsia, and eclampsia. Overweight and obese women also more frequently go through cesarean delivery and give birth a macrosomic infant. Maternal obesity is also found to be associated with greater risk of preterm birth, large-for-gestationalage babies, fetal defects, congenital anomalies and perinatal death. Remarkably, breastfeeding initiation rate and early breastfeeding cessation was found more prevalent among obese women than their healthy weight counterparts. ${ }^{11}$ This finding is true in the context of Bangladesh as well. In a study conducted among Bangladeshi adults found that individuals with higher BMI were more likely to develop hypertension. ${ }^{12}$ Overweight and obese women were at higher risk to develop pregnancy complication like prolonged labor, gestational diabetes, and hypertension and more likely to deliver through cesarean delivery. Therefore, it is also a timely need for physicians, healthcare providers, and policy maker to take necessary steps so that women receive counseling before or during early pregnancy on the adverse health outcome for themselves and for their babies of being overweight or obese.

\section{CONCLUSION}

This study unveils the effect of DBM among Bangladeshi women. These findings suggest that DBM not only affects the women's health but also the health of their children which is alarming. Therefore, concerned stakeholders should stress on this issue and provide imperative intervention to overcome this problem. Findings of this study will offer a strong insight to the policy makers and will help them to set target specific and focused public health interventions accordingly.

\section{REFERENCES}

1. Shrimpton R, Rokx C. The double burden of malnutrition. 2012.

2. Black RE, Victora CG, Walker SP, et al. Maternal and child undernutrition and overweight in low-income and middle-income countries. The lancet. 2013;382(9890):427-451.

3. Victora CG, Adair L, Fall C, et al. Maternal and child undernutrition: consequences for adult health and human capital. The lancet. 2008;371(9609):340-357.

4. Dewey KG, Begum K. Long-term consequences of stunting in early life. Maternal \& child nutrition. 2011;7(s3):5-18.

5. Camilleri AP. The obstetric significance of short stature. European Journal of Obstetrics \& Gynecology and Reproductive Biology. 1981;12(6):347-356. 
6. Sheiner E, Levy A, Katz M, Mazor M. Short stature - an independent risk factor for Cesarean delivery. European Journal of Obstetrics \& Gynecology and Reproductive Biology. 2005;120(2):175-178.

7. Brabin BJ, Hakimi M, Pelletier D. An analysis of anemia and pregnancy-related maternal mortality. The Journal of nutrition. 2001;131(2):604S-615S.

8. Dunn JT. Iodine supplementation and the prevention of cretinism. Annals of the New York Academy of Sciences. 1993;678(1):158-168.

9. Caulfield LE, Zavaleta N, Shankar AH, Merialdi M. Potential contribution of maternal zinc supplementation during pregnancy to maternal and child survival. The American journal of clinical nutrition. 1998;68(2):499S-508S.

10. Burton BT, Foster WR, Hirsch J, Van Itallie TB. Health implications of obesity: an NIH Consensus
Development Conference. International journal of obesity. 1985;9(3):155-170.

11. Marchi J, Berg M, Dencker A, Olander EK, Begley C. Risks associated with obesity in pregnancy, for the mother and baby: a systematic review of reviews. Obesity Reviews. 2015;16(8):621-638.

12. Khanam MA, Lindeboom W, Razzaque A, Niessen L, Milton AH. Prevalence and determinants of prehypertension and hypertension among the adults in rural Bangladesh: findings from a community-based study. BMC public health. 2015;15(1):203.

Cite this article as: Sutradhar I, Hasan M. Exploration of the Health Impact of Double Burden of Malnutrition among Bangladeshi Women. Public Health of Indonesia 2017; 3(4):138-141 